\title{
Willingness of medical students to refer patients to a physician associate or a doctor based on clinical scenarios when time is a trade-off
}

\author{
Pauline Joyce ${ }^{* 1}$, Saifullah Syed ${ }^{1}$, Richard Arnett ${ }^{2}$, Seamus Sreenan ${ }^{1}$, Roderick S Hooker ${ }^{3}$ \\ ${ }^{1}$ Royal College of Surgeons in Ireland, School of Medicine, Dublin, Ireland \\ ${ }^{2}$ Quality Enhancement Office, Royal College of Surgeons in Ireland, Dublin, Ireland \\ ${ }^{3}$ Health Policy Analyst, Ridgefield, WA, USA
}

Received: February 9, 2020

Accepted: May 13, 2020

Online Published: August 25, 2020

DOI: $10.5430 / \mathrm{ijh} . v 7 \mathrm{n} 1 \mathrm{p} 1$

URL: https://doi.org/10.5430/ijh.v7n1p1

\begin{abstract}
Background: The Physician Associate (PA) role was introduced in Ireland in 2015 in an effort to bolster medical services. From the perspective of the patient and staff they have been well received. However, the attitude of medical students about PAs is not known.

Objective: To investigate the willingness of medical students to refer patients to a PA or a doctor.

Methods: A quantitative study was undertaken using an online survey with a sample of 1,909 undergraduate and graduate entry medical students. Based on three outpatient scenarios, they were asked, in their role as future intern (PGY1), to choose a referral to a PA or a doctor, with six time trade-off options offered. Year of study, country of residence and working or treatment experience with PAs and Nurse Practitioners were recorded. Descriptive statistics, and logistic regression models were used.

Results: In 2019, in Dublin, 177 medical students took part in the survey. Those surveyed were international and domestic nationals. Overall the PA option was chosen where the patient's wait time was shorter and the clinical condition was perceived more serious. The doctor option was selected more readily when the wait time difference was less significant. Respondents from countries with established PA roles may have had experience to choose PAs than naïve ones.

Conclusion: This study confirms that medical students' willingness to refer a patient is influenced by familiarity with the PA role and severity of the medical condition. In addition wait time is a primary motivator for selecting the PA over doctor option. These findings suggest a need to improve communication about the PA role among Irish medical students.
\end{abstract}

Key Words: Willingness to refer, Waiting time, Irish, Physician assistant, Medical students, Time trade-off

\section{BACKGROUND}

Physician Associates (PAs) known as Physician Assistants in North America, are considered part of the medical workforce. As of 2019 they number 130,000 in the US, 1,750 in the UK, 600 in Canada, and 450 in the Netherlands. In those settings PAs are deployed in all aspects of medical and surgical care.
Patient acceptance of PAs is positive across four continents and their willingness to see a PA is growing. ${ }^{[1]}$ However, the acceptance of PAs from the perspective of medical students has not been explored. According to Stone (2018) the delivery of quality, cost-effective medical care is increasingly relying upon team-based care. ${ }^{[2]}$ Interprofessional collabora-

*Correspondence: Pauline Joyce; Email: pjoyce@ @rcsi.ie; Address: Royal College of Surgeons in Ireland, School of Medicine, Dublin, Ireland. 
tion and education are strategies recommended to increase the efficacy of health care teams. The Physician Assistant Education Association (PAEA) and the American Academy of Physician Assistants (AAPA) recognise interprofessional education as a key component to the future expansion of the PA profession. ${ }^{[3,4]}$ Reduction of waiting time may influence medical students' decisions when referring patients to another healthcare provider. ${ }^{[5]}$

PAs are utilised in multiple healthcare settings and their contributions have been explored in a wide variety of roles. A national shortage of 46,000 to 90,400 physicians by 2025 was predicted by the Association of American Medical Colleges. ${ }^{[6]}$ As PAs are becoming an increasingly important part of the workforce, growth in their numbers presents a solution to emerging workforce shortages and an ability to help meet increasing healthcare demands. ${ }^{[7]}$ Auerbach et al. found that increased use of Nurse Practitioners (NPs) is a potential solution to physician shortages in many varied medical and surgical settings. ${ }^{[8]}$ The NP and PA workforce in the US have been shown to contribute to health care teams, which is beneficial, giving the increased reliance on teams in new models of care such as accountable care organisations and patient-centred medical homes. ${ }^{[9]}$ One study identified that team-based care that includes PAs and NPs may contribute to a decrease in burnout among doctors. ${ }^{[10]}$ Morgan and colleagues showed that when PAs, NPs, and doctors manage complex patients with a myriad of chronic diseases the long-term outcomes are indistinguishable among the three clinicians. ${ }^{[11,12]}$

This study examined if PAs are acceptable healthcare providers to other medical colleagues, in particular, medical students. PAs were introduced into various societies without asking for input from medical students, with whom they share clinical rotations and bedside teaching. Because PAs are new to Ireland an opportunity to explore the organisational issues of the PA role to medical team-mates for the benefit of the patient is an important undertaking prior to expanding their presence in Ireland. ${ }^{[11]}$

How medical students' background experience and health professions' knowledge influences their referral decisions as future interns remains uncertain and needs to be established before expanding the PA role in Ireland. The inclusion of an interprofessional learning session involving PA students and other undergraduate healthcare professionals found a better understanding of the PA role among some multidisciplinary teams. ${ }^{[13]}$ The impact of introducing physician assistant students to a medical student emergency medicine clerkship found that the experience was viewed as positive overall. One conclusion was that more research is needed to understand and optimise the learning involvement for all learners. ${ }^{[14]}$ Aase et al. observed that medical and nursing students suffer from a lack of mutual knowledge of each other's competence and capabilities in a healthcare setting and that interprofessional teamwork is significantly affected by the professional role identities that the participants play. ${ }^{[15]}$ Yet a recent study found favourable attitudes and openness to interprofessional medical collaboration and education by the PAs. ${ }^{[16]}$ Similar experiences were observed in the UK when Advanced Nurse Practitioners (ANPs) were first introduced, as part of a multidisciplinary team, working on different projects or observing PAs' consultations in action. ${ }^{[17]}$ In summary, the familiarity between the PAs and medical students is unclear and the literature underdeveloped. On the other hand there is some evidence to suggest that increased time spent exploring each other's profession can increase trust, familiarity and interprofessional teamwork. ${ }^{[18]}$

To address this question we surveyed a cohort of undergraduate and graduate entry medical students within the one School of Medicine in Ireland offering a PA programme. The research builds on studies which have explored "willingness to be seen" from the patient's perspective. In an Irish study patients were willing to be seen by a PA if the wait time was shorter, once they had trust in their competency and there was a supervising consultant available if needed. ${ }^{[5]}$ In this investigation, the setting is an academic medical centre that comprises schools of physiotherapy, pharmacy, nursing, and physician associate studies, in addition to other healthcare faculties and schools.

\section{METHODS}

A quantitative study was undertaken using an anonymous online survey of medical students. To maintain consistency with investigation in the area of "willingness to be seen" and time trade-off research, three standardised medical scenarios were presented to participants. A gatekeeper, with no teaching or assessment relationship with the programmes, invited graduate entry and undergraduate medical students to participate in the online survey. Year of study and country of residence of the participants were recorded, together with questions on whether or not they worked with, or were treated by a PA or an NP, the rationale being that there is some overlap in the PA and NP roles. Some students may be more familiar with the PA role than others, based on country of residence before starting medical school, as PAs have been in North America for over 50 years and in Europe since the new century. In their future role as intern (PGY1), participants were given a choice to refer a patient to a PA or a doctor, with different wait times for either provider. Ethical approval was obtained for the study. 


\subsection{Data collection}

In one School of Medicine in Ireland, a sample of 1,909 medical students were targeted. If they opted in, the student was randomly assigned to 1 of 3 patient scenarios. Based on these scenarios, respondents were asked to indicate whether they would be willing to refer the patient in question to a doctor or a PA in relation to varying wait times for the PA. Each circumstance had a fixed doctor waiting time of 2 hours and 1 of 6 different (increasing) PA waiting times.

Prior to answering the questions based on the patient scenario presented, the following information about PAs was included:

Physician Associates (PAs) are healthcare professionals trained in medicine who work in partnership with doctors to provide medical care to patients. They are able to take medical histories, carry out physical examinations, diagnose illnesses, order tests, check results, and formulate treatment plans.

Next, one of the following scenarios was presented:

(1) The patient stepped out of a car into a hole in the footpath and severely injured his ankle. The ankle is swollen, and he is unable to put his weight on the injured foot. When he visits the Emergency Department (ED) you have the option to refer him to a doctor who can review him in 2 hours or the PA immediately. Which one would you choose?

(2) The patient has a $4 \mathrm{~cm}$ cut in the forearm and blood was spurting before he could get a tourniquet on his arm. When he visits the ED you have the option to refer him to a doctor who can review him in 2 hours or the PA immediately. Which one would you choose?

(3) A 4-year-old girl is presented after falling off a swing. She hit her head on a rock and has a $2 \mathrm{~cm}$ gash on her forehead. When she is brought to the ED by her parents you have the option to refer her to a doctor who can review her in 2 hours or the PA immediately. Which one would you choose?

For each scenario, after answering the initial question with the option of seeing a PA immediately and the doctor in 2 hours, the student was offered 5 more options, based on the variation of waiting time to see the PA. The additional waiting times to see the PA varied from 15 minutes to 90 minutes (the waiting time to see the doctor was always 2 hours, i.e., 120 minutes).

\subsection{Data analysis}

Descriptive statistics were used to summarise findings and logistic regression was used to investigate the role of other variables. The primary outcome was the quantification of willingness to refer patients to PAs including the possible influence of variables such as course year, scenario type and previous experience. A secondary outcome was the identification of time thresholds that were evident in the decision process related to referring patients to a PA or a Doctor. Analysis was conducted in $\mathrm{R}^{[19]}$ and figures were produced using the package ggplot2. ${ }^{[20]}$ Statistical significance categories were set at $p<.05(*), p<.01(* *)$ and $p<.001(* * *)$.

\section{RESULTS}

The survey ran four weeks in the summer of 2019. A total of 205 medical students (undergraduate and graduate entry) responded to the survey (11\% response rate). However, some of the responses were incomplete, making the final number 177 (9\% response rate). No significant difference was found between the undergraduate and graduate entry student groups (see Table 1).

Table 1. Number of respondents per programme

\begin{tabular}{llll}
\hline Programme & Year & Count & Total \\
\hline \multirow{4}{*}{ Graduate Entry Medicine } & Declined to say & 2 & \\
& Yr1 & 18 & \\
& Yr2 & 12 & 50 \\
& Yr3 & 11 & \\
& Yr4 & 7 & \\
& PreMed & 15 & \\
Undergraduate Medicine & Yr1 & 35 & \\
& Yr3 & 25 & \multirow{2}{*}{125} \\
& Yr4 & 18 & \\
& Yr5 & 18 & \\
Unknown & Unknown & 2 & 2 \\
\hline
\end{tabular}

Table 2 shows the distribution of students by country of residence prior to starting medical school in Ireland.

Table 2. Country of residence before starting medical school

\begin{tabular}{ll}
\hline Country/Continent & Number of Students \\
\hline Europe (including Ireland/UK) & 60 \\
North America & 55 \\
Middle East & 26 \\
Far East & 23 \\
Other & 13 \\
\hline
\end{tabular}

The organisation in which the study took place has an international student profile. Students attend this institution from 60 countries, different parts of Ireland and are distributed 
across the university's four international campuses and various schools. As reflected in Table 2, the majority of students who responded to the survey come from outside of Ireland. From the students sampled, $58 \%$ had a previous experience of the PA/NP roles, which could influence the responses to the survey.

The majority of participants selected the PA when PA wait time was low (e.g., when the PA was available immediately).
As the PA wait-time increases and the difference between the two providers shortened, the cross-over point appears to be between the PA waiting times of 60 minutes and 90 minutes. When PA wait time was 90 minutes (only 30 minutes less than the doctor wait time), almost two-thirds (64\%) of the survey respondents were willing to wait for the doctor being available. The final logistic regression model results (see Figure $1 \&$ Table 3 ) were via odds ratio (OR) and $95 \%$ confidence intervals $(\mathrm{CI})$.

Incl. Significance and $95 \%$ Confidence Intervals
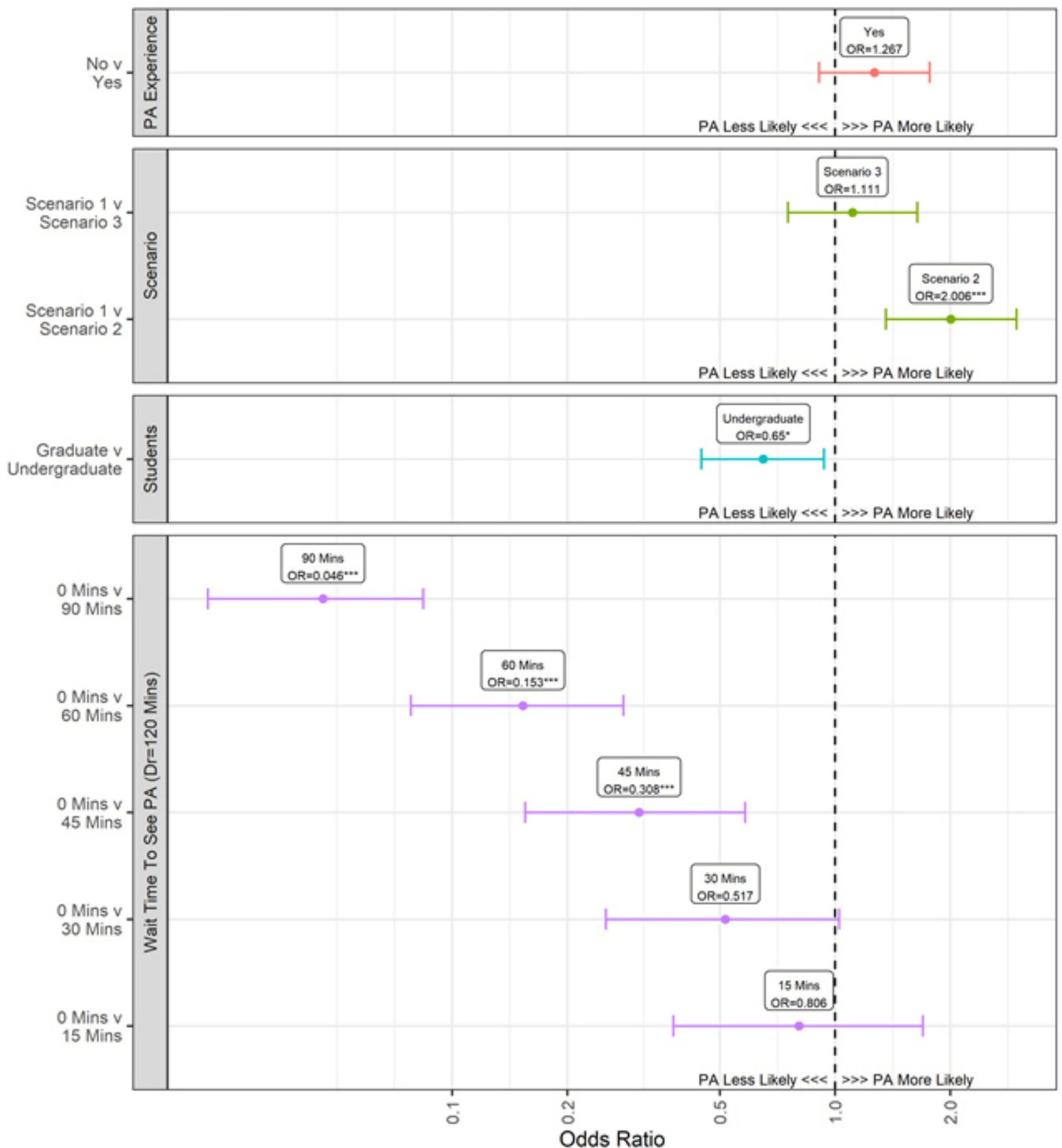

Figure 1. Comparative odds-rations of predictor categories 
Table 3. Logistic regression results

\begin{tabular}{lllllllll}
\hline Predictors & Comparison & Estimate & Std error & Statistic & $\boldsymbol{p}$-value & OR & CI_Lower & CI_Upper \\
\hline Intercept) & NA & 2.398 & 0.341 & 7.037 & .000 & 11.005 & 5.808 & 22.229 \\
Experience-Yes & No v Yes & 0.237 & 0.169 & 1.397 & .162 & 1.267 & 0.909 & 1.767 \\
$\begin{array}{l}\text { Programme-Under } \\
\text { graduate Medicine }\end{array}$ & Graduate v Undergraduate & -0.430 & 0.187 & -2.295 & .022 & 0.65 & 0.448 & 0.935 \\
Scenario-Scenario2 & Scenario 1 v Scenario 2 & 0.696 & 0.200 & 3.479 & .001 & 2.006 & 1.359 & 2.98 \\
Scenario-Scenario3 & Scenario 1 v Scenario 3 & 0.106 & 0.198 & 0.534 & .593 & 1.111 & 0.754 & 1.639 \\
Time-15 Mins (T1) & 0 Mins (T0) v 15 Mins (T1) & -0.215 & 0.380 & -0.567 & .571 & 0.806 & 0.378 & 1.696 \\
Time-30 Mins (T2) & 0 Mins (T0) v 30 Mins (T2) & -0.659 & 0.355 & -1.857 & .063 & 0.517 & 0.252 & 1.024 \\
Time-45 Mins (T3) & 0 Mins (T0) v 45 Mins (T3) & -1.178 & 0.336 & -3.507 & .000 & 0.308 & 0.155 & 0.582 \\
Time-60 Mins (T4) & 0 Mins (T0) v 60 Mins (T4) & -1.879 & 0.323 & -5.816 & .000 & 0.153 & 0.078 & 0.28 \\
Time-90 Mins (T5) & 0 Mins (T0) v 90 Mins (T5) & -3.088 & 0.324 & -9.520 & .000 & 0.046 & 0.023 & 0.084 \\
\hline
\end{tabular}

Overall PAs were selected more often where wait time for a doctor was long, and decreased as the time differences, offered between both practitioners, shortened. Doctors were chosen where the time difference was less. However, in analysing the choice of practitioner, by scenario, a different pattern emerges. Scenario 1 is the ankle injury, scenario 2 is the cut in the forearm and scenario 3 is the four year old child with a gash on her forehead. The data in Figure 2 suggests that the more serious the perceived injury, the more likely respondents are to choose the PA rather than wait for the doctor. So, holding time constant (2-hour wait for the doctor) scenario 2 (laceration) is more likely to result in someone

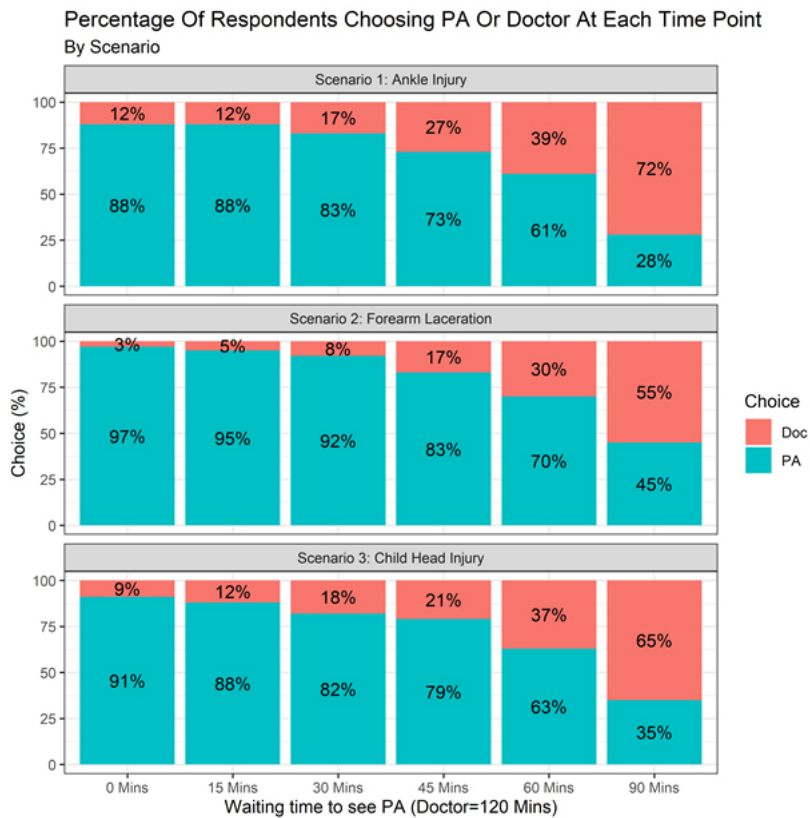

Figure 2. Choice of PA or doctor at each time point by scenario choosing to see a PA than for the other 2 scenarios.

Figure 3 suggests that, compared to undergraduate respondents, a greater proportion of graduate entry respondents were willing to choose a PA, particularly when wait time between the doctor and PA was shorter. Finally, in analysing the choice of practitioner, by previous experience of a PA or NP, a different pattern again emerges. Most students choose a doctor over a PA when they have no experience of this role, i.e., $73 \%$ versus $27 \%$ when the time difference to see either a PA or a doctor differs by only 30 minutes, i.e., 2 hours versus 1.5 hours wait (see Figure 4).

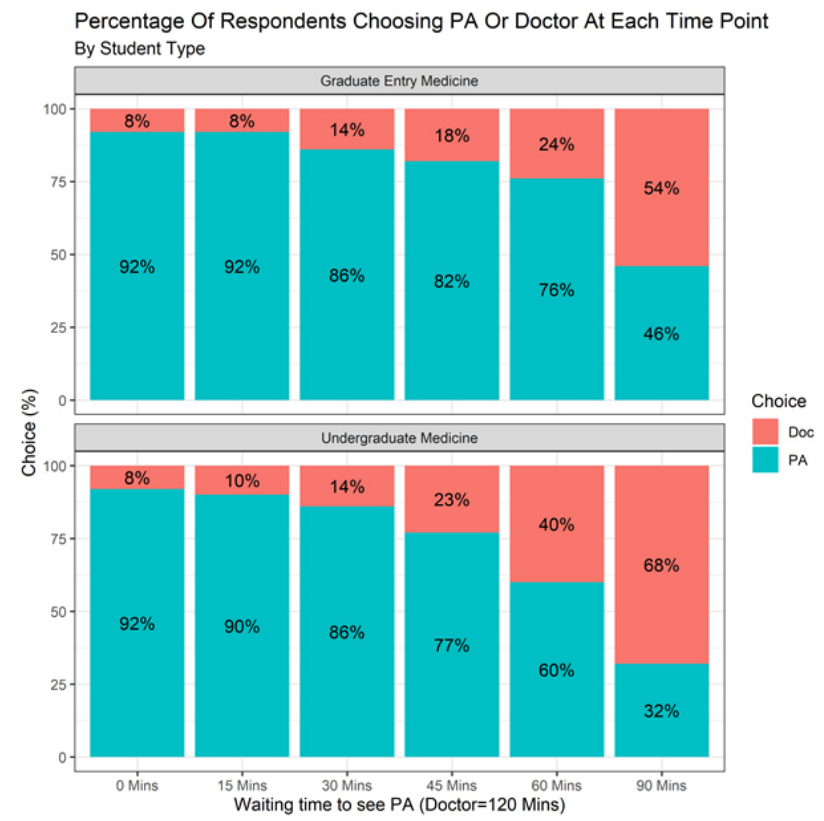

Figure 3. Choice of PA or doctor at each time point by programme 


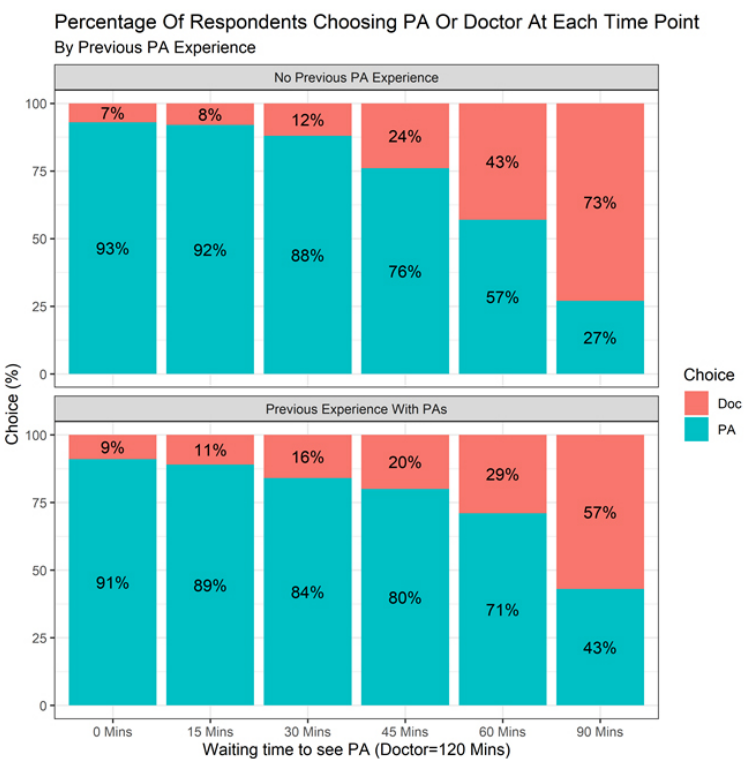

Figure 4. Choice of PA or doctor at each time point by experience

\section{Discussion}

This is the first study of its kind that examines medical students' (as future interns/PGY1) referral choices to a PA compared to a doctor, when time is a trade-off. In prior work the construct of a PA had been presented to surrogate patients who were naïve to what a PA was, and was carried out in five different countries. Regardless of nationality, language, culture, parent status, or age, the patient selected the PA over the doctor when the wait time was significantly shorter. As the wait-times decreased the patient preference shifted more towards the doctor but never exclusively. ${ }^{[21-25]}$

A key factor supporting the emerging role of the PA across many settings is a shortage of doctors and workforce capacity. ${ }^{[26,27]}$ In some settings the focus is more on task shifting. ${ }^{[28]}$ Thus, PAs are included as part of the solution to workforce shortages. ${ }^{[29]}$ The flexibility of the PA role, where he or she is able to step in for doctors to allow them more time on direct patient care, was evaluated as a key benefit for multidisciplinary teams, and concurs with other PA research. ${ }^{[26,28-30]}$ The PA can provide a range of medical skills to support the clinical team allowing the right person to see the right patient, e.g., freeing the consultant or senior doctor up to see more complex patients. In addition the PA can be flexible with taking over the duties of junior doctors who are required to attend training sessions. ${ }^{[31,32]}$ Lee et al. reported on this flexibility particularly when it came to scheduling. ${ }^{[33]}$ Others suggest it is this clinical flexibility that permits PAs to adapt relatively quickly to changing workforce needs and emerging medical practice. ${ }^{[34]}$ Because of their generalist training PAs can shift roles to meet the de- mands of the clinical area, thus adding more adaptability to the scope of practice. ${ }^{[35]}$

The decisions made by the participants in this study were clearly influenced by wait time, especially where the condition was judged to be more serious. Long waiting times has been reported as a problem for EDs worldwide, ${ }^{[36,37]}$ particularly with an increased number of patients attending EDs. ${ }^{[38]}$ If not seen in a timely manner, there is a risk of patients leaving before they are seen and this can be a patient safety concern. In Ireland, the ED wait time target is four hours. ${ }^{[39]}$ Quicker patient throughput is linked with having a PA in ED, ${ }^{[40-42]}$ so employing more PAs in the ED setting may help facilitate achieving this target. Low waiting times and effective practice ensuring patient safety were among findings in a rural setting when the quality of care as delivered by NPs was evaluated. ${ }^{[43]}$

The findings in our study suggest that medical students from countries with established PA roles and those that had previous experience with them are more likely to choose the PA option. However, the degree of familiarity between the PAs and medical students is a topic of interest that needs further exploring. Despite the PA role being in place for over 50 years in the US and the increasing popularity of the profession globally Volpe et al. found that knowledge and perceptions of college students regarding the PA role leaves room for improvement. ${ }^{[44]}$ A Survey of 474 students in one public university in the US found that knowledge of the PA role was higher in older students, female students and those who planned to pursue a healthcare career. However scores did not significantly differ based on whether or not participants were satisfied with prior care from a PA. Based on the questions asked it is notable that less than $50 \%$ of the sample thought that PAs could interpret lab tests or x-ray results, treat patients in the emergency room or treat patients with chronic medical problems. Overall, as the tasks became more complex participants were unsure if PAs could perform these tasks. ${ }^{[44]}$

More specifically, our study site includes a school of nursing and other health professions, as well as medicine. As such, the medical student has many opportunities for interprofessional learning. Nasir et al. study found that an interprofessional learning session between PA and other undergraduate healthcare students facilitated a better understanding of the PA role among the multidisciplinary teams. ${ }^{[45]}$ Likewise, Sytsma et al. investigated the effect of interprofessional education between medical and physical therapy students and found an increased understanding of the other group's professional roles. ${ }^{[13]}$ In addition, the impact of introducing PA students to a medical student emergency medicine 
clerkship concluded that the experience was positive overall. $^{[14]}$ Some studies suggest that differences in attitudes among nursing and medical students can be attributable to pre-professional school socialisation, stereotypes, or programme differences. ${ }^{[15,46]}$ If there is a mutual lack of knowledge between these professions, this may influence the decision to refer a patient to an NP or PA. Traditional patterns of professional roles seem to be still highly prevalent in healthcare teams and may have an impact on several aspects of teamwork, including the participants' predisposition to communicate freely and share responsibility, both of which are considered fundamental pillars of teamwork.

Healthcare students can have preconceived notions and attitudes about the roles of various healthcare practitioners particularly if those students had pre-educational socialisation from family members and friends who are healthcare professionals. ${ }^{[46]}$ However, these attitudes can change and evidence suggests that perception and knowledge among medical students can shift. As healthcare professionals gain more knowledge of the PA role, initial scepticism has given way to seeing PAs as valuable members of the medical team. ${ }^{[47,48]}$

\section{Strengths and limitations}

The willingness of medical students to refer a patient to a PA or a doctor, based on different semi-urgent scenarios, has not been studied previously. The apparent willingness of a small sample of medical students to refer patients to a PA (in theory) within one institution limit the statistical inferences and generalisation of the findings. Sample size was influenced by the timing of the survey, which took cognisance of waiting until after their programme exams and evaluation surveys, had been completed. Unfortunately the survey release ran into vacation periods when students were not as engaged with emails.

While this is a snapshot of medical students' preferences in one institution, it is not known if a bigger sample will expose different outcomes unless scenarios were altered and wait time was closer between the doctor and PA. Although the survey sample included both undergraduate and post graduate students (graduate entry) across different countries, this is the likely sample type in other medical schools globally. There is an opportunity for more research in this area by other academic medical centres.

\section{Conclusions}

In a cross section of medical students in one Irish setting, findings suggest that most are willing (as future interns/PGY1) to refer a patient to a PA, for semi-urgent scenarios, when time is a variable. Therefore, if their patient can see a PA quicker than a doctor, the medical student was motivated to choose the shorter timeframe. The findings of our study suggest that those medical students who were familiar with the PA role, based on previous interactions with the role in their home country, were willing to refer the patient to a PA sooner. This suggests that, providing medical students with more information about the role, which is in its infancy in Ireland, is an important first step. Information of the PA role can commence at induction and can continue right through interprofessional learning sessions which can be spread across all years of medicine. Communicating with all healthcare students regularly about different professionals, with whom they will interact during clinical rotations, should reap rewards later. These communication and learning strategies should make for more integrated multidisciplinary teams, task shifting where necessary, keeping the patient at the centre and avoiding turf wars and silos in patient care.

\section{ETHICS APPROVAL AND CONSENT TO PAR- TICIPATE}

Ethics approval was granted for this study by the RCSI Ethics Committee (REC1670).

\section{FUNDING}

We acknowledge the Royal College of Surgeons in Ireland (RCSI) Research Summer School for funding this study and providing research assistant Saifullah Syed.

\section{ACKNOWLEDGeMENTS}

The authors acknowledge the time taken by the medical students to answer the survey for this study and thanks to the gatekeeper of the study who disseminated the survey.

\section{CONFlicts of InTEREST Disclosure}

The authors declare that they have no conflicts of interest.

\section{REFERENCES}

[1] Hooker RS, Moloney-Johns A, MacFarland M. Patient satisfaction with physician assistant/associate care: An international scoping review. 2019. Human Resources for Health. 17: 104. PMid:31881896. https://doi.org/10.1186/s12960-019-0428-7
[2] Stone J. Moving interprofessional learning forward through formal assessment. Medical Education. 2010; 44(4): 396-403. PMid:20444075. https://doi.org/10.1111/j.1365-2923.2009.03607.x

[3] Thompson BM, Bratzler DW, Fisher MJ, et al. Working together: using a unique approach to evaluate an interactive and clinic-based 
longitudinal interprofessional education experience with 13 professions. Journal of Interprofessional Care. 2016; 30(6): 754-761. PMid:27797628. https://doi.org/10.1080/13561820.2016. 1227962

[4] Levy LA, Mathieson K. Attitudes of Physician Assistant Educators toward Interprofessional Education and Collaborative Care. The Journal of Physician Assistant Education. 2017; 28(2): 72-79. PMid:28437316. https://doi.org/10.1097/JPA. 0000000000 000113

[5] Joyce P, Arnett R, Hill A, et al. Patient willingness to be seen by a physician associate in Ireland. International Journal of Healthcare. 2018; 4(2): 41. https://doi.org/10.5430/ijh.v4n2p41

[6] Association of American Medical Colleges (AAMC). The Complexities of Physician Supply and Demand: Projections From 2017 to 2032. AAMC, Washington, DC. 2019.

[7] Hooker RS, Brock D, Cook M. Characteristics of nurse practitioners and physician assistants in the United States. Journal of the American Association of Nurse Practitioners. 2016; 28(1): 39-46. PMid:26331690. https://doi.org/10.1002/2327-6924.1229 3

[8] Auerbach DI, Chen PG, Friedberg MW, et al. Nurse-managed health centers and patient-centered medical homes could mitigate expected primary care physician shortage. Health Affairs. 2013; 32(11) 1933-1941. PMid:24191083. https://doi.org/10.1377/hlth aff. 2013.0596

[9] Green LV, Savin S, Lu Y. Primary care physician shortages could be eliminated through the use of teams, nonphysicians, and electronic communication. Health Affairs. 2013; 32(1): 11-19. PMid:23297266. https://doi.org/10.1377/hlthaff.2012.1086

[10] Willard-Grace R, Hessler D, Rogers E, et al. Team structure and culture are associated with lower burnout in primary care. Journal of the American Board Family Medicine. 2014; 27(2): 229-238. PMid:24610185. https://doi.org/10.3122/jabfm.2014.02. 130215

[11] Morgan PA, Smith VA, Berkowitz TS, et al. Impact of physicians, nurse practitioners, and physician assistants on utilization and costs for complex patients. Health Affairs. 2019; 38(6): 1028-1036 PMid:31158006. https://doi.org/10.1377/hlthaff .2019.0 0014

[12] Everett CM, Morgan P, Smith VA, et al. Primary care provider type: Are there differences in patients' intermediate diabetes outcomes. JAAPA. 2019; 32(6): 36-42. PMid:31136399. https ://doi .org/ 10.1097/01. JAA.0000558239.06875.0b

[13] Sytsma TT, Haller EP, Youdas JW, et al. Long-term effect of a short interprofessional education interaction between medical and physical therapy students. Anatomical Sciences Education. 2015; 8(4): 317-23. PMid:26040635. https://doi.org/10.1002/ase.1546

[14] Turner J, Corson-Knowles D, Besinger B, et al. Experience introducing physician assistant students into a medical student emergency medicine clerkship. Journal of Interprofessional Education \& Practice. 2019; 1(14): 1-5. https://doi.org/10.1016/j.xjep. 201 8.10 .005

[15] Aase I, Hansen B, Aase K. Norwegian nursing and medical students' perceptions of interprofessional teamwork: a qualitative study. BMC Medical Education. 2014; 14(1): 1-9. PMid:25124090. https://doi.org/10.1186/1472-6920-14-170

[16] Johnson SW, Mathieson K. The effects of demographics on physician assistant attitudes and openness towards interprofessional medical collaboration and education. Journal of Interprofessional Care. 2020; 19. https://doi.org/10.1016/j.xjep.2020.100333

[17] Jackson B, Marshall M, Schofield S. Barriers and facilitators to integration of physician associates into the general practice workforce: a grounded theory approach. British Journal of General Practice. 2017; 67(664): e785-e791. PMid:28993304. https://doi .org/10.339 9/bjgp17X693113

[18] Nagelkerk J, Thompson ME, Bouthillier M, et al. Improving outcomes in adults with diabetes through an interprofessional collaborative practice program. Journal of Interprofessional Care. 2018; 32(1): 4-13. PMid:29111835. https://doi.org/10.1080/1356 1820.2017 .1372395

[19] R Core Team. R: A language and environment for statistical computing. R Foundation for Statistical Computing, Vienna, Austria. URL. 2017.

[20] Wickham H. ggplot2: Elegant Graphics for Data Analysis. SpringerVerlag New York. 2019.

[21] Hooker RS, Harrison K, Pashen D. Are Australians willing to be treated by a physician assistant? Australasian Medical Journal. 2010; 3(7): 407-413. https ://doi .org/10.4066/AMJ . 2010.325

[22] Doan Q, Hooker RS, Wong H, et al. Will Canadians accept care by physician assistants? Canadian Family Physician. 2012; 58(7): e459-464.

[23] Kuilman L, Nieweg RMB, van der Schans CP, et al. Are Dutch patients willing to be seen by a physician assistant instead of a medical doctor? Human Resources for Health. 2012; 10(9): 34 40. PMid:22947130. https://doi .org/10.1186/1478-4491-1 $0-28$

[24] Larkin GL, Hooker RS. Patient willingness to be seen by physician assistants, nurse practitioners, and residents in the emergency setting: does the presumption of assent have an empirical basis? American Journal of Bioethics. 2010; 10(8): 1-10. PMid:20694894. https://doi.org/10.1080/15265161.2010.494216

[25] Berkowitz O, Hooker RS, Nissanholtz-Gannot R, et al. Israeli willingness to be treated by a physician assistant. 2020. Journal of Health Policy. PMid:32405904. https ://doi .org/10.1007/s10900-0 20-00835-7

[26] Drennan VM, Halter M, Wheeler C, et al. What is the contribution of physician associates in hospital care in England? A mixed methods, multiple case study. BMJ Open. 2019; 9(e027012). PMid:30700491. https://doi.org/10.1136/bmjopen-2018-027012

[27] Joyce P, Woodmansee D, O'Neill JP. The physician associate: a role in Irish healthcare. Forum. 2019; (September): 17.

[28] Brink vd GTWJ, Kouwen AJ, Hooker RS, et al. An activity analysis of Dutch hospital-based physician assistants and nurse practitioners. Human Resources for Health. 2019; 17(78): 1-8. PMid:31665010. https://doi .org/10.1186/s12960-019-0423-z

[29] Jackson B, Marshall M, Schofield S. Barriers and facilitators to integration of physician associates into the general practice workforce: a grounded theory approach. British Journal of General Practice. 2017; 67(664): e785-e791. PMid:28993304. https://doi.org/10. 339 9/bjgp17X693113

[30] De Bruijn-Geraets DP, van Eijk-Hustings YJL, Bessems-Beks MM, et al. National mixed methods evaluation of the effects of removing legal barriers to full practice authority of Dutch nurse practitioners and physician assistants. BMJ Open. 2018; 8(e019962). PMid:29934382. https://doi.org/10.1136/bmjopen-2017-019962

[31] Dies N, Rashid S, Shandling M, et al. Physician assistants reduce resident workload and improve care in an academic surgical setting. Journal of the American Academy of Physician Assistants. 2016; 29(2): 41-46. PMid:26818645. https://doi.org/10.1097/01 .JAA. 0000476214.34937 .50

[32] Halter M, Wheeler C, Drennan VM, et al. Physician associates in England's hospitals: a survey of medical directors exploring current usage and factors affecting recruitment. Clinical Medicine. 2017; 
17(2): 126-31. PMid:28365621. https://doi.org/10.7861/cl inmedicine.17-2-126

[33] Lee B, D'Souza M, Singman EL, et al. Integration of a Physician Assistant Into an Ophthalmology Consult Service in an Academic Setting. American Journal of Ophthalmology. 2018; 190: 125-133. PMid:29604282. https://doi.org/10.1016/j.ajo.2018.03. 033

[34] Hooker RS, Cawley JF, Leinweber W. Physician assistant career mobility and the potential for more primary care. Health Affairs. 2010; 29(5): 880-886. PMid:20439875. https : //doi.org/10.1377/hl thaff.2009.0884

[35] Cawley JF, Hooker RS. Physician assistant role flexibility and career mobility. JAAPA. 2010; 23(8): 10. PMid:20821905. https : //doi.org/10.1097/01720610-201008000-00001

[36] Drennan VM, Halter M, Brearley S, et al. Investigating the contribution of physician assistants to primary care in England: a mixedmethods study. Health Services and Delivery Research. 2014; 2(16): 2050-4349. PMid:25642506. https://doi.org/10.3310/hsdr 02160

[37] Szeto MCH, Till A, McKimm J. Integrating physician associates into the health workforce: barriers and facilitators. British Journal of Hospital Medicine. 2019; 80(1): 12-17. PMid:30592669. https://doi.org/10.12968/hmed.2019.80.1.12

[38] Theunissen BH, Lardenoye S, Hannemann PH, et al. Fast Track by physician assistants shortens waiting and turnaround times of trauma patients in an emergency department. European Journal of Trauma in Emergency Surgery. 2014; 40: 87-91. PMid:26815782. https ://doi .org/10.1007/s00068-013-0324-0

[39] Houses of the Oireachtas Committee on the Future of Healthcare. Sláintecare Report, Houses of the Oireachtas, Dublin. 2017.

[40] Oliveira MM, Marti C, Ramlawi M, et al. Impact of patient-flow physician coordinator on waiting times and length of stay in an emergency department: A before-after cohort study. PLoS ONE. 2018; 13(12): e0209035. PMid:30550579. https ://doi .org/10.1371/ journal.pone. 0209035
[41] Johnson KD, Winkelman C. The effect of emergency department crowding on patient outcomes: a literature review. Advanced Emergency Nursing Journal. 2011; 33(1): 39-54. PMid:21317697. https : //doi.org/10.1097/TME.0b013e318207e86a

[42] Doetzel CM, Rankin JA, Then KL. Nurse practitioners in the emergency department: Barriers and facilitators for role implementation. Advanced Emergency Nursing Journal. 2016; 38: 43-55. PMid:26817430. https://doi.org/10.1097/TME.0000000000 000090

[43] McDevitt J, Melby V. An evaluation of the quality of Emergency Nurse Practitioner services for patients presenting with minor injuries to one rural urgent care centre in the UK: a descriptive study. Journal of Clinical Nursing. 2014; 24: 523-535. PMid:24891126. https://doi.org/10.1111/jocn. 12639

[44] Volpe M, Bulmer S, Kelsey C. Knowledge and perceptions of college students regarding the Physician Assistant profession. Cureus. 2015; 7(10): e368. PMid:26623223. https ://doi.org/10.7759/cure us. 368

[45] Nasir J, Goldie J, Little A, et al. Case-based interprofessional learning for undergraduate healthcare professionals in the clinical setting, Journal of Interprofessional Care. 2017; 31: 1, 125-128. PMid:27918867. https://doi.org/10.1080/13561820.2016.1233395

[46] Lindberg O. Undergraduate socialization in medical education: Ideals of professional physicians' practices. Learning in Health and Social Care. 2009; 8: 241-249. https://doi .org/10.1111/j.1473-6 861.2009.00228.x

[47] Wheeler C, Halter M, Drennan VM, et al. Physician associates working in secondary care teams in England: Interprofessional implications from a national survey. Journal of Interprofessional Care [Online]. 2017; 31(6): 774-776. PMid:28876145. https : //doi.org/10.1080/13561820.2017.1341390

[48] Delunas L, Rouse S. Nursing and Medical Student Attitudes about Communication and Collaboration Before and After an Interprofessional Education Experience. Nursing Education Perspectives. 2014; 35(2): 100-105. PMid:24783725. https ://doi .org/10.5480/11 $-716.1$ 